transfer processes in emergency situations]. Metody i sredstva komp'juternogo modelirovanija IPMJe NANU: sb. trudov - Methods and means of computer modeling IPME NASU: collection of articles. works. Kiev.58 - 60 [in Russian].

Volodumur Suvolapov, Senior Lecturer, Andriy Novitskiy, Assoc. Prof., PhD tech. sci., Vasul Khmelevski, Assoc. Prof., DSc., Oleksandr Bustruy, Senior Lecturer

National University of Life and Environmental Sciences of Ukraine, Kyiv, Ukraine

\title{
Investigation of the Heat Transfer Process in Internal Combustion Engine Cylinders
}

The article analyzes scientific publications and literary studies of heat transfer processes in cylinders of internal combustion engines. The research of temperature fields in engines during their operation at different modes with the use of a software package and calculation module is presented. The results of modeling and thermo-metering in homogeneous and laminated engine cylinder liners are analyzed. Graphic dependencies and temperature distribution by cylinder wall thickness at maximum and minimum temperature on cylinder surface are given.

On the basis of researches it is established that at laminating and pressing of inserts temperature fields in the engine cylinder change, temperature on an internal surface of the cylinder increases at laminating on 6,5 ${ }^{\circ} \mathrm{C}$, and at pressing - on $4,5^{\circ} \mathrm{C}$. This is explained by the fact that the contact layer during plastification is in the zone of non-stationary mode, and when pressing the contact layer is in the zone of stationary mode and thus increases the thickness of the cylinder by 2 millimeters. It is established that the difference of minimum and maximum temperatures on the inner surface of the cylinder practically remains the same as that of a homogeneous cylinder.

Thus, modeling becomes the most effective scientific tool in the development and implementation of long-term evaluation of options for improving ICE.

engine, sleeve, repair, restoration, plating, heat transfer

Одержано (Received) 06.10.2020

Прорецензовано (Reviewed) 12.10.2020

Прийнято до друку (Approved) 19.10.2020

УДК 621.89

DOI: https://doi.org/10.32515/2664-262X.2020.3(34).274-281

Є.К. Солових, проф., д-р техн. наук, В.О. Дубовик, доц., канд. техн. наук, В.В. Пукалов, доц., канд. техн. наук, Ю.А. Невдаха, доц., канд. техн. наук, А.М. Середа Центральноукраӥнський національний технічний університет, м. Кропивницький, Україна e-mail: zenesperanto@gmail.com

\section{Підвищення якості припрацювання деталей двигунів автомобілів при обкатці застосуванням присадки комплексної дії}

У роботі обгрунтовано, що для підвищення якості та прискорення припрацювання деталей двигунів автомобілів при обкатці потрібна комплексна присадка, що включає як поверхнево-активні так і хімічно-активні речовини. Розглянуто передумови отримання плівок перенесення на поверхнях тертя сполучень двигуна при обкатці. Проведено порівняльні лабораторні дослідження запропонованої присадки.

Застосування запропонованої присадки комплексної дії сприяє зміні структури поверхневого шару металу в процесі тертя під дією температури і навантаження, що призводе до підвищення якості припрацювання деталей двигунів автомобілів при обкатці.

обкатка, припрацювання, масло, присадка, вибірковий перенос, тертя, спрацювання

(С) С.К. Солових, В.О. Дубовик, В.В. Пукалов, Ю.А. Невдаха, А.М. Середа, 2020 
Е.К. Соловых, проф., д-р техн. наук, В.А. Дубовик, доц., канд. техн. наук, В.В. Пукалов, доц., канд. техн. наук, Ю.А. Невдаха, доц., канд. техн. наук, А.Н. Середа

Центральноукраинский национальный технический университет, г.. Кропивниикий, Украина

Повышение качества приработки деталей двигателей автомобилей при обкатке использованием присадки комплексного действия

В работе обосновано, что для повышения качества и ускорения приработки деталей двигателей автомобилей при обкатке необходима комплексная присадка, которая включает как поверхностноактивные так и химическо активные вещества. Рассмотрены предпосылки получения пленок переноса на поверхностях трения сопряжений двигателя при обкатке. Проведены сравнительные лабораторные исследования предложенной присадки.

Применение предложенной присадки комплексного действия способствует изменению структуры поверхностного слоя металла в процессе трения под действием температуры и нагрузки, что приводит к повышению качества приработки деталей двигателей автомобилей при обкатке.

обкатка, приработка, масло, присадка, выборочный перенос, трение, износ

Постановка проблеми. В умовах станцій технічного обслуговування, досягти конструктивними заходами прискорення і підвищення якості припрацювання деталей двигунів дуже складно і не завжди економічно доцільно. Технологічні заходи потребують значних матеріальних затрат, висококваліфікованих спеціалістів і дорогого обладнання. Тому одним 3 перспективних напрямків покращення якості припрацювання є експлуатаційні заходи.

При цьому науково обгрунтовані режими обкатки двигуна, які дозволяють підвищити якість припрацювання поверхонь тертя. Все це впливає на довговічність двигуна і його експлуатацію з підвищеним ресурсом.

Огляд літературних джерел вказує на те, що хімотологічний склад присадок різного типу і процесів, які протікають на робочих поверхнях деталей двигунів при обкатці потребує подальших досліджень.

Аналіз основних досліджень і публікацій. Значний науковий і практичний внесок у вдосконалення процесів припрацювання деталей двигунів мають роботи М.П. Воінова, Д.М. Гаркунова, А.С. Гуревича, В.В. Долбіна, В.Ф. Карпенкова, Р.В. Кугеля, I.M. Крагельського, С.С. Некрасова, В.В. Стрельцова, Н.В. Храмцова, В.І. Ципцина, Г.П. Шаронова та інші. Згідно їх досліджень за своєю фізико-хімічною дією припрацювальні присадки можна розділити на ряд груп:

- інактивні речовини (IP);

- поверхнево-активні речовини (ПАР);

- хімічно-активні речовини (ХАР);

- композиції, які сприяють вибірковому переносу (КСВП).

Широке розповсюдження отримали металоплакувальні присадки, які використовують явище вибіркового перенесення (ВП) металу при терті, відкрите Гаркуновим Д.Н. і Крагельським І.М. Явище ВП засноване на тому, що при певних умовах спостерігається утворення плівок перенесення (антифрикційних плівок) металів із складу присадок, які забезпечують низький коефіцієнт тертя і зниження спрацювання деталей [1].

Аналіз досліджень по підвищенню надійності двигунів після ремонту при обкатці показав, що в умовах авторемонтних підприємств найбільш економічними i ефективними $\epsilon$ експлуатаційні заходи по прискоренню припрацювання деталей двигуна, які полягають в застосуванні комплексних присадок до масла і повітря. Це дозволяє знизити припрацювальний знос і тим самим збільшити ресурс двигуна в цілому. Аналіз присадок для припрацювання деталей двигунів після ремонту виявив найбільш перспективним використання комплексних присадок, які містять ПАР і ХАР. 
Постановка завдання. Метою роботи є підвищення якості процесу припрацювання деталей двигунів автомобілів при обкатці застосуванням присадки комплексної дії.

Завданнями є теоретичне обгрунтування утворення плівок перенесення при обкатці двигунів і проведення порівняльних досліджень розробленої комплексної присадки до моторного масла М-8-В.

Виклад основного матеріалу. Прискорення припрацюваня деталей засноване на адсорбційному зниженні міцності металу при реалізації ефекту Ребіндера [2]. До таких речовин відносять: олеїнову кислоту, гліцерин, ефіри органічних кислот.

При описі контактної взаємодії будемо використовувати поняття молекулярних сил. Крагельським I.B. у загальне рівняння сили тертя, поряд 3 механічною компонентою, введена молекулярна складова [3].

В останні роки різко зросла кількість робіт в яких граничний шар мастильного середовища 3 прилягаючими плівками на твердих контактуючих поверхнях розглядається як один з основних факторів взаємодії $[4,5]$.

У дослідженнях, пов'язаних 3 вибірковим перенесенням використовується комплексний підхід до розуміння фрикційної взаємодії з позиції фізико-хімічної механіки, основи якої були закладені Ребіндером П.А. [6].

Наявність ефективних методів дослідження структури і складу поверхневих шарів дозволило отримати результати, які використовують при описі процесу зношування як комплексу процесів руйнування вихідних структур, формування нових i їх руйнування. Це викликало створення теорій фрикційної взаємодії на основі описання процесів масопереносу при терті.

В даній роботі будемо використовувати одну з таких теорій, запропоновану Д.I. Ригні [7]. Згідно його досліджень була запропонована модель тертя і вираз для коефіцієнта тертя:

$$
\begin{aligned}
& \mu(h)=[1-f(h)] \frac{(n \cdot A)^{e}}{P}\left\{\tau_{\max }^{e}\left[F\left(\frac{\tau_{s}^{e}}{\tau_{\text {max }}^{L}}\right)-\exp \left(-\alpha^{e} \cdot h\right) \cdot F\left(\frac{\tau_{1}}{\tau_{\max }^{e}}\right)\right]+\right. \\
& \left.+\tau_{\max } \cdot \exp \left(-\alpha^{e} \cdot h\right) \cdot F\left(\frac{\tau_{1}}{\tau_{\max }}\right)\right\}+f(h) \frac{n \cdot A}{P} \cdot \tau_{\max } \cdot F\left(\frac{\tau_{1}}{\tau_{\max }}\right) .
\end{aligned}
$$

де $\mathrm{h}$ - товщина перенесеної плівки; $\tau_{\text {s }}$ - опір зсуву на поверхні вільній від плівки; $\tau_{\mathrm{s}}^{e}$ - опір зсуву на поверхні плівки; $\tau_{1}$ - опір зсуву між плівкою і поверхнею деталі; $\tau_{\max }^{e}$ - опір зсуву у плівці переносу; А - площа одиничного контакту; $n$ - число контактів; P - нормальне навантаження; f(h) - доля нерівностей, які вільні від плівки; $\alpha$ - коефіцієнт, що характеризує зниження пластичності у плівці перенесення; е показник, який характеризує властивості плівки перенесення.

Приведений вираз враховує тертя у перенесеній плівці, в основному матеріалі під плівкою і у матеріалі вільному від плівки. Він описує фрикційну взаємодію у тому випадку, коли м'яка плівка перенесення міцна закріплена на основному матеріалі, а поверхня ковзання співпадає 3 межею розділу плівки і контртіла. Однак при зсуві можуть спостерігатись такі випадки, коли площина ковзання буде знаходитись в середині плівки або на межі розділу плівки і основного матеріалу. У цьому випадку створюються умови для відшарування перенесеного матеріалу. Тому, більш загальним випадком фрикційної взаємодії є утворення перенесеної плівки на обох поверхнях тертя деталей (рис. 1) 


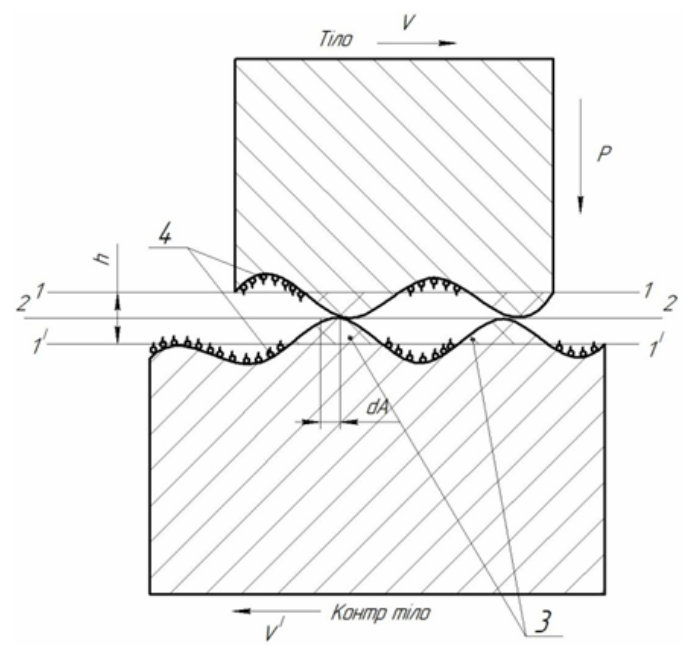

1-1, (1'-1') - межі розділення перенесеної плівки і поверхневого шару металу тіл; 2-2 - межа розділення на рівні «плівка-плівка», перенесена на взаємодіючі тіла; 3 - плівки перенесені на поверхні тіл тертя;

4 - адсорбований і хемосорбований шар масла; v, v'- швидкості руху; Р - навантаження; $\mathrm{dA}$ - площа одиничного контакту; $\mathrm{h}$ - товщина перенесених плівок.

Рисунок 1 - Схема фрикційної взаємодії поверхонь вкритих плівками перенесення Джерело: розроблено авторами з використанням [1, 3, 4, 6]

Структура плівки перенесення характеризується суттєвою неоднорідністю, великим числом пор, які $\epsilon$ мікрорезервуарами для змащувального матеріалу. Дрібнодисперсні частки металу 3 активною поверхнею служать також центрами утворення полімероподібних продуктів. Присутність в зоні контакту поверхневоактивних речовин з металами приводе до реалізації особливого механізму фрикційної взаємодії, що характеризується колоїдною системою часток у змащувальному матеріалі і структурним перетворенням на поверхні розділу (згідно досліджень Стрельцова В.В.). Це приводе до швидкої адаптації пари тертя і переходу іiі у усталений режим роботи.

При терті шорсткості робочих поверхонь піддаються впливу пружних i пластичних деформацій, що супроводжується структурними перетвореннями та появою дислокацій. В результаті збільшується вільна поверхнева енергія, що викликає перетворення речовин і активацію хімічних реакцій.

Зміна часу життя міжатомного зв'язку під навантаженням в залежності від напруження $\sigma$ і температури Т описується рівнянням С.М. Журкова:

$$
\tau=\tau_{0} \cdot \exp \frac{\mathrm{U}_{0}-\gamma \cdot \sigma}{k \cdot T},
$$

де $\tau$ - час до руйнування, с;

$\tau_{0}-$ період теплових коливань атомів, с;

$\mathrm{U}_{0}$ - величина енергетичного бар'єру, Дж; $\sigma$ - напруження, мПа;

$\mathrm{k}$ - стала Больцмана $\left(\mathrm{k}=1,38 \cdot 10^{-23}\right.$ Дж/К);

$\gamma$ - коефіцієнт, який характеризує властивості міцності твердого тіла;

Т - абсолютна температура, К.

Для коефіцієнту тертя f, аналогічне рівняння буде мати вигляд:

$$
f=f \cdot \exp \frac{\mathrm{U}_{0}-\gamma \cdot \sigma}{k \cdot T}
$$

Хімічне модифікування поверхонь тертя (сюди ж можна віднести процес вибіркового перенесення) залежить від наявності у змащувальному матеріалі хімічноактивних речовин, які взаємодіють з металічними поверхнями і знижують схильність поверхонь до утворення металічних зв'язків, що запобігає схоплюванню і підвищеному 
зношуванню при важких режимах тертя. У якості критерію, який враховує хімічну модифікацію використовують наступне співвідношення:

$$
\Pi_{\text {гp.x. }}=\frac{\mathrm{R} \cdot T}{U},
$$

де $U$ - енергія активації розпаду міжатомних зв'язків хімічно модифікованих шарів, Дж;

Т - абсолютна температура, К;

$\mathrm{R}$ - універсальна газова постійна, $\mathrm{R}=8,31$ Дж/моль.

Зносостійкість поверхні буде залежати від співвідношення швидкості стирання модифікованих шарів і їх утворення у процесі тертя, від фізико-хімічних властивостей цих шарів, їх розмірів (товщини і глибини).

3 точки зору енергетичних перетворень утворення рівновісного стану відбувається пропорційно приросту енергії активації $\mathrm{d}\left(\mathrm{A}_{\mathrm{a}}\right)$ в одиницю часу (згідно досліджень Стрельцова В.В.), який визначається:

$$
10 \mathrm{adA}_{\mathrm{a}}=\frac{\mathrm{dS}}{d t}=\mathrm{a}\left(\frac{\mathrm{dA}_{\mathrm{T}}}{\mathrm{dt}} \cdot \frac{d A_{0}}{d t}\right)
$$

де а - постійний коефіцієнт, с/H; S - площа контакту, м²;

$\mathrm{dA}_{\mathrm{T}}-$ енергія тертя, Дж; $\mathrm{dA}_{0}-$ енергія, яка відводиться, Дж.

При постійній площі контакту $(\mathrm{dS} / \mathrm{dt}=0)$ процес переходе у рівновісний стан. В процесі припрацювання енергія, яка відводиться, змінюється по складному закону і при деякому критичному значенні $\mathrm{S}=\mathrm{S}_{\text {кр }}$ досягає граничного значення $\mathrm{i}$ остається незмінною або зменшується.

Процеси контакту, тертя і зношування, як правило, пов'язані з безпосередніми фізичними взаємодіями поверхонь при їх відносних переміщеннях. На ці процеси впливає мастильне середовище, яке виконує наступні функції: розділяє поверхні тертя і зменшує безпосереднього контакту металічних поверхонь; змінює пластичні властивості взаємодіючих поверхонь; охолоджує поверхні тертя і змиває з них або вимиває із зазорів частки металів і їх оксиди, які оказують абразивний вплив на поверхні тертя. При наявності плівок перенесення, поверхні, що труться переміщуються одна відносно іншої з малим опором зсуву і без пошкоджень. В залежності від товщини плівки $\left(10^{-3} \ldots 10^{-2}\right.$ мкм), розподіл в ній поверхонь профілів і ступеню геометричного прилягання поверхонь виникають різні режими змащування.

Основне призначення масел для обкатки полягає у створенні між рухомими поверхнями плівки, яка здатна зменшити число прямих взаємодій твердих тіл і характеризується малим опором зсуву. Граничне змащення повинне володіти високою адгезією до поверхні тертя, зменшувати зношування і володіти малою міцністю на зріз, що забезпечує мале тертя.

Взаємодія твердого тіла $з$ маслом, що приводе до появи захисної граничної плівки представляється трьома механізмами: фізичною і хімічною адсорбцією, хімічною реакцією.

Тому для підвищення якості і прискорення припрацювання потрібна комплексна присадка, яка включає в себе і ПАР і ХАР. Виходячи з цього нами пропонується покращена комплексна присадка за основу якої взято розроблений і запатентований склад для обробки пар тертя (патент на корисну модель №125160, Україна [8]), що має наступний склад у відсотках по масі:

- олеїнова кислота $\mathrm{C}_{17} \mathrm{H}_{33} \mathrm{COOH}-2,0 \%$;

- літієвий ферит із зворотною структурою шпінелі $\mathrm{Fe}\left[\mathrm{Li}_{0,5} \mathrm{Fe}_{1,5}\right] \mathrm{O}_{4}-0,5 \%$;

- тетраборат етилендиамонія $\left[\mathrm{C}_{2} \mathrm{H}_{4}\left(\mathrm{NH}_{3}\right)_{2}\right] \mathrm{H}_{4} \mathrm{~B}_{4} \mathrm{O}_{9}-0,3 \%$;

- октадецилсульфанат натрію $\mathrm{C}_{18} \mathrm{H}_{37} \mathrm{SO}_{3} \mathrm{Na}-0,2 \%$; 
- мінеральне масло - до 100\%.

Для перевірки припрацювальних якостей запропонованої присадки проводили порівняльні випробування на зношування на установці СМТ-1 за схемою «роликколодка». Використовували масло М-8-В з розробленою присадкою. Визначали залежності моментів сили тертя від часу випробувань (рис. 2)

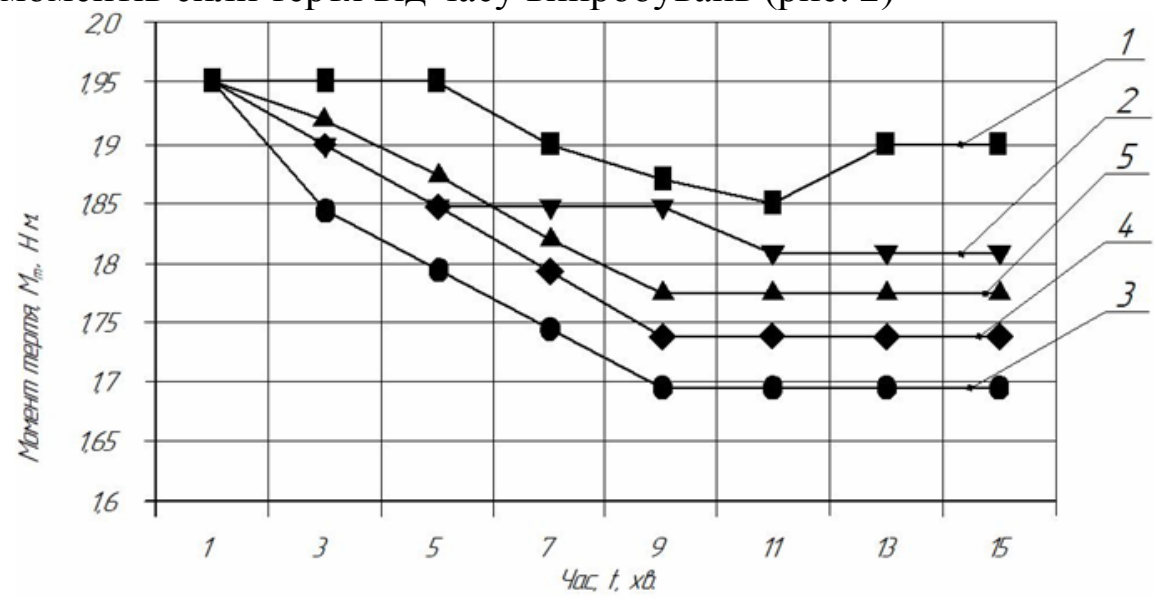

склад 1 - Масло М-8-В (температура - 333 К); склад 2 - Масло М-8-В + присадка 3 \% (температура - 333 К); склад 3 - Масло М-8-В + присадка 3 \% (температура - 293 К - 5 хв. і 333 К - 10 хв.); склад 4 - Масло

М-8-В + присадка 3\% (температура - 293 К); склад 5 - бензин АИ-92 + присадка 3\% (температура - $293 \mathrm{~K}$ ).

Рисунок 2 - Залежність моменту сили тертя від часу випробувань при $\left(\mathrm{n}=500 \mathrm{xB}^{-1} ; \mathrm{P}=600 \mathrm{H} ; \mathrm{t}=15\right.$ хв.)

Джерело: розроблено авторами

3 наведеного графіку видно, що зниження моменту сили тертя на маслі М-8-В відбувається на п'ятій хвилині і по мірі припрацювання знижується не суттєво. Додавання у моторне масло присадки сприяє інтенсивному формуванню оптимальної мікрогеометрії i, відповідно, інтенсивному зниженню, а також більш швидкій стабілізації моменту сили тертя. У цьому випадку зниження моменту сили тертя спостерігається $з$ першої хвилини, а стабілізація відбувається на 9 - 11 хвилинах. На протязі часу, в наслідок пластифікування сполучених поверхонь твердих тіл поверхнево-активними речовинами i малої твердості захисних покриттів, які утворюються, фактична площа контакту збільшується. Це приводе до зменшення питомого навантаження і температури в зоні контакту.

Також визначали шорсткість поверхні зразків припрацьованих на різних складах (табл. 1) і їх мікротвердість (рис. 3).

Шорсткість поверхонь після припрацювання свідчить про формування оптимальної мікрогеометрії з'єднання. В результаті обробки профілограм були отримані наступні характеристики шорсткості зразків.

Таблиця 1 - Результати оцінки шорсткості припрацьованих поверхонь.

\begin{tabular}{|l|c|c|c|}
\hline \multirow{2}{*}{ Склад } & \multicolumn{3}{|c|}{ Параметри шорсткості, мкм } \\
\cline { 2 - 4 } & $\mathrm{R}_{\mathrm{MAX}}$ & $\mathrm{R}_{\mathrm{z}}$ & $\mathrm{R}_{\mathrm{a}}$ \\
\hline Масло M-8-B & 5,30 & 2,5 & 1,8 \\
\hline Масло М-8-B + присадки 3\% & 2,50 & 0,85 & 0,6 \\
\hline
\end{tabular}


Зразки, для визначення мікротвердості, були припрацьовані на наступних режимах $\mathrm{n}=500 \mathrm{xB}^{-1} ; \mathrm{P}=780 \mathrm{H} ; \mathrm{t}=60$ хв.

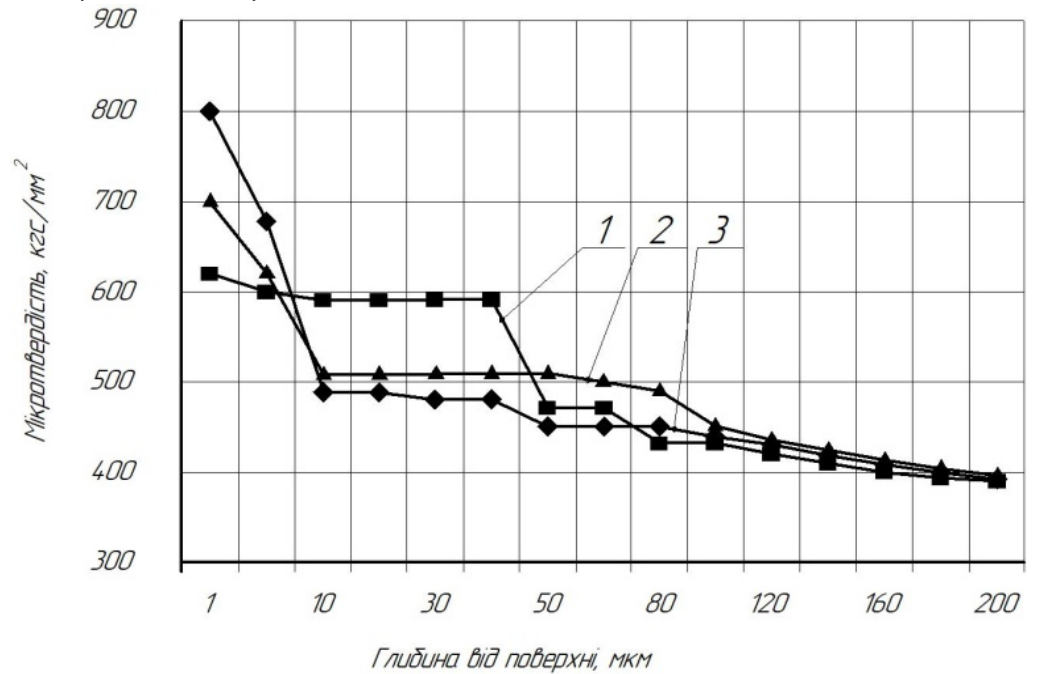

склад 1 - Масло М-8-В (температура - 333 К); склад 2 - Масло М-8-В + присадка 3 \% (температура - 333 К); склад 3 - Масло М-8-В + присадка 3 \% (температура - 293 К).

Рисунок 3 - Залежність мікротвердості по глибині від поверхні зразків

Джерело: розроблено авторами

Збільшення мікротвердості поверхні тертя (поверхневих шарів) свідчить про ефективність присадки.

Висновки. Виявлено, що застосування запропонованої присадки комплексної дії формує металоплакуюче покриття на робочих поверхнях деталей та сприяє зміні структури поверхневого шару металу в процесі тертя під дією температури i навантаження. Чим підвищується якість процесу припрацювання деталей двигунів автомобілів при обкатці.

\section{Список літератури}

1. Радин Ю.А., Суслов П.Г. Безызносность деталей машин при трении. Ленинград: Машиностроение, 1989. $229 \mathrm{c}$.

2. Варнаков В.В., Стрельцов В.В., Попов В.М., Карпенков В.Ф. Технический сервис машин сельскохозяйственного назначения. Москва: Колос, 2000.56 с.

3. Крагельский И.В., Михин Н.М. Узлы трения машин: справочник. Москва: Машиностроение, 1984. $280 \mathrm{c}$.

4. Белый А.В., Прокопенко Г.Д., Мышкин Н.К. Структура и методы формирования износостойких поверхностных слоев. Москва: Машиностроение, 1991. 208 с.

5. Справочник по триботехнике: в 3 т. Теоретические основы / под общ. Ред.. М. Хебды, А.В. Чичинадзе. Москва: Машиностроение, 1990. Т. 1. 480 с.

6. Ребиндер П.Я. Поверхностные явления в дисперсных системах. Физико-химическая механика: Изб. Труды. - Москва: Наука, 1989. 381 с.

7. Rigney D.A., Chen L.H., Naylor M.G., Spesivsev A.A. In Proc. Of the 1986. Int. Powder Metallyrgy Conf. and Exhibition «The Future of Powder Metallyrgy». Dusseldorf, 1986. p. 835 - 838.

8. Склад для обробки пар тертя: пат. на корисну модель №125160 Україна, опубл. 25.04.2018 р., бюл. №8.

\section{Referencis}

1. Radin, Yu.A. \& Suslov, P.G. (1989). Bezyiznosnost detaley mashin pri trenii [Non-wear of machine parts during friction]. Leningrad: Mashinostroenie [in Russian]. 
2. Varnakov, V.V., Streltsov, V.V., Popov, V.M. \& Karpenkov, V.F. (2000). Tehnicheskiy servis mashin selskohozyaystvennogo naznacheniya [Technical service of agricultural machinery]. Moskow: Kolos [in Russian].

3. Kragelskiy, I.V. \& Mihin, N.M. (1984). Uzlyi treniya mashin [Friction units of machines]. Moskow: Mashinostroenie [in Russian].

4. Belyiy, A.V., Prokopenko, G.D. \& Myishkin, N.K. (1991). Struktura $i$ metodyi formirovaniya iznosostoykih poverhnostnyih sloev [Structure and methods of formation of wear-resistant surface layers]. Moskow: Mashinostroenie [in Russian].

5. Hebdyi, M. Chichinadze, A.V. (1990). Tribotechnics Handbook. Theoretical Foundations (Vols. 1-3; Vol. 1). Moskow: Mashinostroenie [in Russian].

6. Rebinder, P.Ya (1989). Poverhnostnyie yavleniya $v$ dispersnyih sistemah. Fiziko-himicheskaya mehanika: Izb. Trudyi [Surface phenomena in dispersed systems. Physico-chemical mechanics]. Moskow: Nauka [in Russian].

7. Rigney, D.A., Chen, L.H., Naylor, M.G. \& Spesivsev, A.A. (1986). In Proc. Of the 1986. Int. Powder Metallyrgy Conf. and Exhibition «The Futre of Powder Metallyrgy». Dusseldorf [in English].

8. Pat. N125160 Ukraine. Sklad dlia obrobky par tertia [Composition for processing friction pairs]. Has been published April 25, 2018, Bul. N8 [in Ukrainian].

Yevhen Solovykh, Prof., DSc., Viktor Dubovyk, Assoc. Prof., PhD tech. sci., Viktor Pukalov, Assoc. Prof., PhD tech. sci., Yurii Nevdakha, Assoc. Prof., PhD tech. sci., Andrii Sereda

Central Ukrainian National Technical University, Kropyvnytskyi, Ukraine

\section{Improving the Quality of Running-in of Car Engine Parts During Running-in Using a Complex Action Additive}

The purpose of the work is to improve the quality of the process of running-in of car engine parts during running-in using the additive of complex action. The tasks are the theoretical substantiation of the formation of transfer films during engine running-in and the conduct of comparative studies of the developed complex additive to M-8-B motor oil.

The paper substantiates that in order to improve the quality and accelerate the running-in of car engine parts during running-in, a complex additive is required, which includes both surfactants and chemically active substances. The preconditions for obtaining transfer films on the friction surfaces of engine connections during running-in are considered. A frictional interaction is described in the case when the soft transfer film is strong and fixed on the main material, and the sliding surface coincides with the boundary between the film and the counter body. The presence in the zone of contact of surfactants with metals leads to the implementation of a special mechanism of frictional interaction, characterized by a colloidal system of particles in the lubricant and structural transformation on the interface.

Comparative laboratory studies of the proposed additive were performed. The dependence of the moment of friction force on the time of the tests, the surface roughness of the samples worked in different compositions, as well as the distribution of the microhardness of the samples by depth were investigated.

Based on the analysis of additives for running-in of engine parts, the use of complex additives containing surfactants and chemically active substances is determined as promising. Based on these studies, an additive containing ferrite spinel has been proposed. This allows you to control the running-in process through the structurally sensitive properties of the spinel composition. The use of the proposed additive of complex action helps to change the structure of the surface layer of the metal during friction under the action of temperature and load, which leads to improved quality of running-in of car engine parts during running-in.

running-in, running-in, oil, additive, selective transfer, friction, wear 